\title{
Informal institutions, transaction risk, and firm productivity in Myanmar
}

\author{
Michael Danquah • Kunal Sen
}

Accepted: 16 November 2020 / Published online: 21 January 2021

(C) UNU-WIDER 2021

\begin{abstract}
In many low-income transition countries, where formal institutions such as courts do not function effectively, informal institutions are often used by firms to minimize transaction risks. We examine the role of informal institutions, in the forms of relational contracting and social networks, in determining the risks that firms are willing to bear in their transactions with their suppliers and customers, and whether firms that bear such risks have higher productivity. Our country context is Myanmar, a country which is making a transition from a socialist to market-oriented economy. Using a unique dataset of 2496 micro, small, and medium firms, we find that firms that engage in risk taking are significantly more productive than firms that do not, and such firms are more likely to utilize informal institutions, such as acquiring information from informal interaction with customers, and social networks, including information received from business networks by firms, talking to other suppliers of customers, and being a member of a business association. Our findings suggest that informal institutions can be effective substitutes for formal institutions that are often absent or not effective in low-income transition economies.
\end{abstract}

M. Danquah · K. Sen

UNU-WIDER, Helsinki, Finland
Keywords Firm productivity - Informal institutions · Relational contracting $\cdot$ Social networks $\cdot$ Transition economies $\cdot$ Myanmar

JEL classifications $\mathrm{O} 12 \cdot \mathrm{O} 43 \cdot \mathrm{P} 26 \cdot \mathrm{L} 26$

\section{Introduction}

What explains the productivity of firms in developing countries? Several studies have examined the role of factors internal to the firm such as technology, human capital, research and development investment, and managerial practices, as well as external factors such as trade reforms, competition, and foreign direct investment (Syverson 2011). The new institutional economics literature has also highlighted the role of institutions in explaining firm productivity. As this literature argues, well-specified and enforced property rights and efficient contracting institutions formed the institutional architecture that is the bedrock of productivity and living standard gains (North 1994a). An emerging literature has highlighted the role of formal institutions such as formal

\footnotetext{
K. Sen $(\bowtie)$

Global Development Institute, University of Manchester,

Manchester, UK

e-mail: sen@wider.unu.edu
} 
property rights, simplified business registration processes, and well-functioning courts and credit bureaus in determining firm productivity in developing countries (Bloom et al. 2014; Dethier et al. 2011; World Bank 2020).

While such formal institutions are expected to exist and function to some extent in middle-income countries, they are less likely to be observed in low-income countries. This would particularly be the case in low-income transition economies which are emerging from a prolonged period of isolation from the outside world and from socialistic practices which forbid the existence of private enterprise towards a market-oriented economics. Since the laws of contracts are often inadequate, informal institutions can substitute for formal institutions in allowing firms in these economies to undertake crucial economic exchanges that are necessary for their survival and growth (Grief 2006; McMillan 1997; McMillan and Woodruff 1999). In such economies, firms depend on the goodwill of other firms and of their customers for their business. Social networks that provide information to the firm about the reliability of their suppliers and their customers are a key set of informal institutions for maintaining business trust (Steer and Sen 2010). Relational contracts that take the form of repeated, ongoing relationships between firms, suppliers, and customers provide a means of informal enforcement in the absence of courts and formal dispute resolution mechanisms (Fafchamps 2016).

However, relatively little is known about the role of informal institutions, such as social networks and relational contracting, in determining firm productivity in low-income country contexts where formal institutions either do not exist or function poorly. One important reason for the paucity of studies in this area is the lack of reliable data that can provide robust measures of firm productivity for micro and small firms in low-income countries. In addition, measures of informal institutions, such as social networks and relational contracts, are often difficult to obtain and questions about the functioning of informal institutions are not conventionally included in firm surveys undertaken by national statistical agencies.

In this paper, we examine the role of informal institutions in determining firm productivity in a low-income country which has made the move recently from a socialist economy to a market-based economy. The country we study is Myanmar, a low-income country in South East Asia, which is re-integrating with the world economy after several decades of economic isolation and centralized socialistic controls on private enterprises. Economic reforms have been underway in Myanmar since 2011, and laws have been passed to encourage the growth of the private sector. However, even though the Myanmar government has simplified business registration in recent years and does well in the ease of doing business (Myanmar does better than the regional average in the World Bank's Doing Business indicators), it has weak creditor rights and does poorly in contract enforcement. Therefore, for private firms in Myanmar, formal contracting institutions are weak, and firms need to rely on informal institutions when engaging in transactions with their suppliers and customers. We assess whether informal institutions, such as relational contracts and social networks, allow firms to take on a degree of risk in their transactions and whether firms that take on such risk are more likely to be productive than firms that do not.

A strength of our paper is that we have a survey of 2496 micro, small, medium, and large firms in Myanmar which provides detailed information on firms' sales and the inputs they purchase, allowing us to construct robust measures of firm productivity. Unusually for firm surveys in low-income countries, the questionnaire asks firms about their reliance on family and friends, the strength of their informal ties with their customers, and the social networks they rely on for their everyday business. Finally, the survey also asks firms whether they have made a specific investment in equipment or trained workers, specifically to supply a particular customer, which we use as a measure of the assumed risk of firms.

The paper uses the stochastic frontier analysis approach to investigate the impact of the assumed risk of firms - the risk that firms willingly bear in transactions with their customers-on firm productivity in Myanmar. Secondly, we examine the role of informal institutions in explaining the assumed risk of firms. The findings reveal that the assumed risk of firms significantly increases firm productivity in Myanmar. Firms that engage in risk taking are significantly more productive than firms that do not. Firms that utilize informal institutions, such as acquiring information from informal interaction with customers and social networks, including information received from business networks by firms, talking to other suppliers of customers, and being a member of business association, have a higher 
propensity to take larger assumed risk with respect to transactions with their customers.

The remainder of the paper proceeds as follows. Section 2 presents an overview of the reform process in Myanmar. The conceptual framework for the paper is discussed in Section 3. Section 4 contains the methodological approach. Section 5 discusses the source of the data used for this paper and presents some descriptive statistics. Section 6 provides the empirical results and discussion. Section 7 presents the concluding remarks and policy implications.

\section{Myanmar's reform process}

In 1962, the Revolutionary Council (RC) led by General Ne Win overthrew the parliamentary government of the time and introduced a centrally planned system. The RC was openly hostile to business, banning private enterprise in 1963 (Turnell 2009). It nationalized much of the private sector, including agricultural and industry, wholesale and retail trade, and banking (Tin 2006). Private imports were banned in 1963 and exports in 1964 (Tin 2006). The introduction of socialism in Myanmar led to 'the end of institutions serving the functioning of the market system, such as the laws of property, and of contract, the legal system of courts and lawyers, and the monetary and banking institutions that provided the financial framework of the market system' (Khin et al. 2000: 189).

By the mid-1980s, socialism had led to economic stagnation (Bissinger 2014). The economic crisis culminated in protests in 1988, leading to the resignation of General Ne Win and the coming to power of a military junta - the State Law and Order Restoration Council (SLORC). The junta took steps to move the economy away from central planning by legalizing the role of markets in the economy. The SLORC focused on the development of local firms that were in the nascent stage after three decades of socialism and encouraged both domestic and foreign investment in the private sector while privatizing a number of state-owned enterprises (OECD 2015). However, the state maintained a controlling role in the managed transition to a market-oriented economy through state-owned enterprises and widespread economic controls (Tin 2006).

The reform process intensified in 2011 under the leadership of Thein Sein with the move to a managed floating exchange rate in 2012 and the extension of international banking licences to a range of private banks, thereby reducing the role of state-owned banks in the domestic financial system. The government also reduced barriers to trade, removing import and export licencing requirements for selected goods. Furthermore, in 2012, the government passed a new Foreign Investment Law (FIL) to attract foreign direct investment, which included enhanced tax incentives, new arbitration mechanisms, and greater clarity on the structure of investment partnerships (Bissinger 2014). In 2013, the government passed a revised Citizen Investment Law, which extended the benefits of the FIL to local investors.

However, notwithstanding the new set of reforms initiated since 2011, the basic legal and regulatory framework for business is still provided by the colonial era Companies Act (1914) and associated rules (1940) and regulations (1957) (UNESCAP 2015). A number of line ministries plus various local municipal authorities are involved in the licencing of individual businesses and supervision of different industries. As a consequence, Myanmar's regulatory and policy framework remains fragmented and less transparent, with businesses having to deal with a number of parallel line ministries that often fail to adequately coordinate activities between themselves (OECD 2013).

The mixed record of the reform process in promoting an enabling environment for private domestic firms to grow is apparent in the World Bank's Doing Business Report 2020 (World Bank 2020). As Table 1 indicates, Myanmar does well in the time taken to start a business or to obtain a construction permit ( 7 days to start a business or 88 days to obtain a construction permit in Myanmar, compared to the regional averages of 25.6 and 132.2 days respectively). However, when it comes to creditor rights and the enforcement of contracts, Myanmar does badly. With respect to legal rights and credit registry coverage, its strength of legal rights is 2, compared to 7.1 for East Asia and the Pacific (EAP), and its credit registry coverage is zero, compared to $16.6 \%$ for EAP. With respect to the enforcement of contracts, it takes 1160 days to enforce a contract in Myanmar, compared to the EAP average of 581.1 days, and its quality of judicial processes is 4.0 , compared to the EAP coverage of 8.1. This suggests that the functioning of formal institutions is very weak in Myanmar, which could be a huge impediment for firms to engage in market transactions. 
Table 1 Doing business indicator, Myanmar and East Asia and the Pacific

\begin{tabular}{lcccccc}
\hline $\begin{array}{l}\text { Doing } \\
\text { business } \\
\text { indicator }\end{array}$ & $\begin{array}{l}\text { Time taken to start a } \\
\text { business, men (days) }\end{array}$ & $\begin{array}{l}\text { Time taken to obtain a } \\
\text { construction permit } \\
\text { (days) }\end{array}$ & $\begin{array}{l}\text { Strength of legal } \\
\text { rights (index, } 0- \\
12)\end{array}$ & $\begin{array}{l}\text { Credit registry } \\
\text { coverage (\% of } \\
\text { adults) }\end{array}$ & $\begin{array}{l}\text { Enforcing } \\
\text { contracts } \\
\text { (days) }\end{array}$ & $\begin{array}{l}\text { Quality of judicial } \\
\text { processes (index, 0- } \\
18)\end{array}$ \\
\hline $\begin{array}{l}\text { Myanmar } \\
\begin{array}{l}\text { East Asia } \\
\text { and the }\end{array}\end{array}$ & 7 & 88 & 2 & 0 & 1160 & 4.0 \\
Pacific & 25.6 & 132.3 & 7.1 & 16.6 & 581.1 & 8.1 \\
\hline
\end{tabular}

Source: World Bank (2020)

\section{The conceptual framework}

In this section, we sketch out a conceptual framework to understand the relationships between informal institutions, assumed risk, and productivity. Our argument in the paper is based on two propositions. The first proposition is that firms that are more willing to assume risk are likely to be more productive. The second proposition is that, in the absence of well-functioning formal institutions, informal institutions play a key role in mitigating risk faced by firms. We discuss the rationale for each of these two propositions in turn.

\subsection{The relationship between assumed risk and firm productivity}

We draw from the Transactions Cost Economics (TCE) framework pioneered by Oliver Williamson (1985, 1996) to posit a relationship between assumed risk and firm productivity. The TCE framework holds that economizing on transactions costs is responsible for the choice of one organization over another (Williamson 1996). The TCE approach differs from the neoclassical approach in not treating firms as production functions. Instead, firms and markets are alterative methods of coordinating production and minimizing transactions costs (Coase 1937; Williamson 2010). Therefore, firm behaviour is a function of the underlying economic environment in which firms transact with other economic agents (Shelanski and Klein 1995). This implies that firm productivity should not be seen as purely determined by technological factors and is affected in large part by the institutional environment.

The TCE approach is particularly relevant in the context of a transition economy where formal institutions of property rights and contracting institutions may not be present. The experience of the transition economies in Central and Eastern Europe and Russia in their attempt to move to market economies in the 1990 s suggests that the most difficult element in the reform process was the development of a legal system and formal institutions that would be conducive to the preservation of private property and the functioning of a market economy (Svejnar 2002). ${ }^{1}$ Given the absence or lack of third party institutions such as courts to enforce contracts in transition economies, the TCE approach gives primacy to informal institutions of 'private ordering' as the mechanism by which firms address the inherent uncertainty in their economic exchanges with other firms and customers (Williamson 2010).

According to the TCE framework, firms face two specific types of risk in their economic exchanges. The first is in the transactions that they have with their suppliers where they lack information about the reliability of their suppliers in delivering the inputs in time. In addition, they face uncertainty about the quality of inputs that they purchase from these suppliers. The second is in the risk that firms face when they sell their products to their customers, in the proper settlement of the dues that they may have to incur in the act of sales (Steer and Sen 2010). There is also a risk associated with the monitoring and enforcement of agreements that firms may have with their customers in the production of certain goods.

While an earlier literature took the transaction risks that firms face in their exchanges with suppliers and customers as exogenous (Boerner and Macher 2001), the TCE framework treats these risks as endogenous as they involve a degree of choice by the firm, and depend on the firm's ability to assume these risks (Williamson 1996). This may be termed as 'assumed risk'-the risk that firms willingly bear in the transactions with their

\footnotetext{
${ }^{1}$ See also Gogokhia and Berulava (2020) who show that a better business environment provides a stimulus for firms to invest in innovations in transition economies.
} 
customers and their suppliers. A commonly used measure of assumed risk is asset specificity - the degree to which an asset can be redeployed to alternative uses and by alternative users without sacrifice of productive value (Williamson 1996). Asset specificity can take several forms:

'... site specificity, where successive stations are located in a cheek by jowl relation to each other so as to economize on inventory and transportation expenses; physical asset specificity, such as specialized dyes that are required to produce a component; human asset specificity, that arises in a learning by doing fashion; and dedicated assets, which are discrete investments in general purpose plant that are made at the behest of a particular customer' (Williamson 1996: 59-60).

A large literature on the determinants of firm productivity has found that asset- or relationship-specific investments, such as those that firms make in training their workers and in specialized machinery and equipment, are associated with higher productivity of the firm (Bloom et al. 2014; McKenzie and Woodruff 2014; Syverson 2011). For example, on-the-job training for workers leading to learning by doing allows producers to identify opportunities for process improvements (Syverson 2011). Investment in specialized machinery and equipment that embodies the most advanced technological knowledge leads to large spillover effects and has been shown to be associated with higher productivity growth (De Long and Summers 1991, 1992). Hall et al. (2013) find that information and communication technology (ICT) investment, which is an example of an asset-specific investment, is associated with productivity in the case of Italian manufacturing firms. ${ }^{2}$ Pellegrino and Piva (2020) find that younger firms in sectors where investments are more likely to be asset-specific such as bio-tech, medical instruments, and information and health-intensive industries are more effective in translating research and development into innovation.

While the above literature suggests that there is a positive association between asset specificity or assumed risk and firm productivity, it does not make clear why some firms may choose to invest in specific assets

\footnotetext{
$\overline{2}$ Børing (2019) finds that a firm's productivity level is related to its potential corporate social responsibility objectives for innovation, which may be seen as another form of an asset-specific investment.
}

while other firms do not. We next turn to the question of what determines the firm's propensity to assume risks.

\subsection{The determinants of assumed risk}

The new institutional economics literature posits that the institutional architecture of the economy will determine whether firms are willing to bear a higher degree of assumed risk. As North (1994b: 3) notes, 'in order to realize the gains from the productive potential associated with a technology of increasing returns, one has to invest enormous amounts in transacting'. Transaction costs can be both 'the costs of acquiring information on the multiple dimensions of what is being exchanged (and) also the costs of enforcing contracts and making credible commitments across time and space' (North 1994b: 3). Where a well-functioning legal system exists, ongoing relationships between firms can supplement formal contracts for economic exchange to occur smoothly (McMillan and Woodruff 1999). Better enforcement of contracts ex post is likely to lead to less under-investment in relationship-specific investments ex ante, making the firm more productive (Nunn 2007). However, where the legal system is inadequate, informal institutions of information acquisition and relational contracting can substitute for formal institutions for transactions to occur. We discuss three sets of informal institutions that can mitigate transaction risks for firms, especially in low-income country settings.

\subsubsection{Mechanisms of information acquisition}

When formal mechanisms of information acquisition do not exist, firms use informal means such as frequent visits and communication with their suppliers and customers. Long-term relationships that firms have with other firms and customers are also important ways to learn about their partners' reliability over time (Steer and Sen 2010). These long-term relationships that are repeated over time can be termed as relational contracts and have two main advantages: they economize on the costs of finding new matches and enable agents to deal in a more trusting manner (Fafchamps 2016). The threat of losing this valuable relationship deters firms from breaching the informal contract between the firm and its supplier or customer. The fear of exploitation increases with a lower degree of trust between the firm and its suppliers and customers, and in one off relationships (Hwang 2006). We hypothesise that firms that 
have a means of acquiring information or are embedded in long-term relationships will be more willing to bear a degree of assumed risk.

\subsubsection{Social networks}

Social networks can be of two types: informal interactions with family and friends and membership of business associations. These networks provide information on customers' reliability as well as mechanisms of social sanctions on customers or suppliers who renege (McMillan and Woodruff 1999). For example, the threat of no further trade if debts are not paid has additional impact if it comes not just from the firm but also from other agents in the network (Kandori 1992). Information shared by members of a social network allows for community sanctions against errant firms and provides a 'private order contract enforcement mechanism' in the absence of formal dispute resolution procedures (Grief 2006).

The literature on social capital pioneered by Putnam (2000) also provides insights on why social networks matter for entrepreneurship development. This literature argues that social capital characterized by social networks provide the context within which firms are embedded, and facilitate higher trust among individuals, thereby reducing uncertainties in contracts (EscandonBarbosa et al. 2019). We hypothesise that firms that have access to social networks will be more willing to bear a degree of assumed risk.

\subsubsection{Locked-in behaviour}

If few alternative suppliers are available, for example due to high search costs or high transportation costs, a customer can be locked in a relationship (Steer and Sen 2010). If the customer is locked in, the firm can threaten to cut off further economic exchange if debts are not paid. Lock-ins make relational contracts workable (McMillan and Woodruff 1999). We hypothesise that greater competition will decrease the possibility of lockins for a firm and make them more willing to bear a degree of assumed risk.

\section{Methodology}

In this section, we first present the methodology used in computing firm productivity and discuss the empirical strategy in the analysis of the correlates of firm productivity. We then describe the empirical specification we estimate to examine the relationship between assumed risk and institutions.

\subsection{Estimation of firm efficiency and relationship between firm efficiency and assumed risk}

The empirical approach used to estimate firm efficiency and the impact of assumed risk of firms on firm efficiency is the parametric stochastic frontier analysis (Aigner et al. 1977; Kumbhakar and Lovell 2000). To do this, we design and estimate five different stochastic frontier models in order to compute 'accurate' efficiency estimates of firms in Myanmar. We start with a baseline homoscedastic model, followed by four modified versions of heteroscedastic stochastic frontier models. The heteroscedastic stochastic frontier models are important to this exercise because ignoring the heterogeneity in the stochastic frontier production model may cause biased estimates of the frontier function parameters as well as estimates of inefficiency (see Greene 2004; Hadri et al. 2003).

The baseline model is a standard cross-sectional stochastic frontier model:

$$
\begin{aligned}
& \mathrm{y}_{\mathrm{i}}=\beta^{\prime} \mathrm{x}_{\mathrm{i}}+\mathrm{v}_{\mathrm{i}}-\mathrm{u}_{\mathrm{i}}, \mathrm{ui}=|\mathrm{U}| \\
& v i \sim \mathrm{N}\left[0, \sigma_{\mathrm{v}}^{2}\right] \\
& U \sim \mathrm{N}+\left[0, \sigma_{\mathrm{u}}^{2}\right],
\end{aligned}
$$

where $y_{i}$ is the output of the firm (log total sales), $\beta^{\prime}$ is the parameter to be estimated, $x_{i}$ represents a set of production inputs (log labour force, $\log$ capital stock) and type of technology - hand tools, manual, only power, and both power and manually driven. $\beta^{\prime} x_{i}+v_{i}$ is the optimal, frontier goal (in this case maximal production output) pursued by firms, $\beta^{\prime} \mathrm{x}_{\mathrm{i}}$ is the deterministic part of the frontier, and $v_{i}$ embodies measurement errors, any statistical noise, and random variations of the frontier across firms (the stochastic part). The deterministic and stochastic part put together constitutes the 'stochastic frontier'. $-u_{i}$ is the measure of the shortfall of output from the frontier for each observed firm in the sample. In this analysis, $-u_{i}$ is technical inefficiency and is assumed to be normal half normal while $v_{i}$ is assumed to be normally distributed. The choice of normal half normal assumption for $-u$ follows from the literature (see Greene 1990; Ruggiero 1999; and Kumbhakar and Lovell 2000) which indicates that the distributional 
assumption does not influence the inefficiency estimates of the stochastic frontier model. Also, the Vuong test and correlation plots for inefficiency estimates for the normal half normal, exponential, and gamma distributions using our baseline model show that there is no difference in inefficiency estimates across distributional assumptions (see Table A1 and Figs. A1 and A2 in Online Appendix A.1). As firms may use different technologies, in this case of Myanmar, estimating a common frontier function encompassing every sample observation may not be appropriate because the estimated technology is not likely to represent the true technology. If these unobserved technological differences are not taken into account during estimation of the frontier function, the effects of these omitted unobserved technological differences may be inappropriately labelled as inefficiency (see Parmeter and Kumbhakar 2014). As a result, an important feature of our specification in Eq. (1) is the inclusion of heterogeneous technologies for firms based on the type of technology used by the firm as part of the production inputs $x_{i}$.

As a result of the questions raised over the suitability of the Cobb-Douglas functional form and the inclination for the Translog stochastic frontier specification (see Danquah and Ouattara 2015; Duffy and Papageorgiou 2000), we apply the Translog specification to characterize the production frontier (see also Table 2 for a test of Cobb-Douglas against the Translog using a likelihood-ratio (LR) test). The literature on firm productivity, particularly on Myanmar, shows that factors such as location in industrial zone and access to sufficient infrastructure, more precisely electricity supply, are associated with the productivity of the firm (see Greenstone et al. 2010; Min and Kudo 2013; Robertson and Taung 2015; Hu et al. 2015; Rand et al. 2019). In building the heteroscedastic models, we introduce these significant firm-level characteristics ( $h_{l}$ - location in an industrial zone and access to electricity from the grid) that may affect the production process in Myanmar. The first heteroscedastic stochastic frontier model introduces $h_{i}$ in the frontier function itself. The stochastic frontier function can be specified as:

$$
\begin{aligned}
& y_{i}=\beta^{\prime} x_{i}+\alpha^{\prime} h_{i}+v_{i}-u_{i}, \mathrm{ui}=|\mathrm{U}| \\
& v i \sim \mathrm{N}\left[0, \sigma_{\mathrm{v}}^{2}\right] \\
& \mathrm{U} \sim \mathrm{N}\left[0, \sigma_{\mathrm{u}}^{2}\right] .
\end{aligned}
$$

Table 2 Generalized likelihood-ratio (LR) tests

\begin{tabular}{llll}
\hline Null hypothesis $\left(H_{\mathrm{o}}\right)$ & $\begin{array}{c}\text { LR-test } \\
\text { statistics }\end{array}$ & $\begin{array}{l}\text { Critical value } \\
(\alpha=0.05)\end{array}$ & Decision \\
\hline $\begin{array}{l}\text { No efficiency effects } \\
\text { A Cobb-Douglas func- } \\
\text { tion is adequate }\end{array}$ & 53 & 2.706 & $\begin{array}{c}\text { Reject } \\
H_{\mathrm{o}}\end{array}$ \\
\hline
\end{tabular}

The critical values are at $5 \%$ level of significance and are obtained from Table 1 of Kodde and Palm (1986)

In the second heteroscedastic frontier model, we introduce heterogeneity in the mean of the underlying distribution of $u_{i}$ (the truncation model). This is specified as:

$$
\begin{aligned}
& y_{i}=\beta^{\prime} x_{i}+v_{i}-u_{i}, \text { ui }=|\mathrm{U}| \\
& v i \sim \mathrm{N}\left[0, \sigma_{\mathrm{v}}^{2}\right] \\
& U \sim \mathrm{N}\left[\alpha^{\prime} h_{i}, \sigma_{\mathrm{u}}^{2}\right] .
\end{aligned}
$$

The third and fourth heteroscedastic models allow observable variation $h_{i}$ in the variance of $u_{i}\left(\sigma_{u}{ }^{2}\right)$ and $v_{i}$ $\left(\sigma_{v}{ }^{2}\right)$ respectively (see Hadri et al. 2003). In this case, given a frontier model as shown in Eq. (3), the variance functions of $u_{i}$ and $v_{i}$ can be specified as $\operatorname{Var}\left[u \mid h_{i}\right]=$ $\sigma_{\mathrm{u}}^{2} \exp .\left(\Omega^{\prime} h_{i}\right)$ and $\operatorname{Var}\left[v \mid h_{i}\right]=\sigma_{\mathrm{v}}{ }^{2} \exp .\left(\delta^{\prime} h_{i}\right)$ respectively. Therefore, the heterogeneity in variance of $u_{i}$ model can be specified as:

$$
\begin{aligned}
& y_{i}=\beta^{\prime} x_{i}+v_{i}-u_{i}, \mathrm{ui}=|\mathrm{U}| \\
& \operatorname{vi} \sim \mathrm{N}\left[0, \sigma_{\mathrm{v}}^{2}\right] \\
& U \sim \mathrm{N}\left[0, \sigma_{\mathrm{u}}^{2} \exp \left(\Omega^{\prime} h i\right)\right] .
\end{aligned}
$$

The heterogeneity in variance of $v_{i}$ model can also be written as:

$$
\begin{aligned}
& y_{i}=\beta^{\prime} x_{i}+v_{i}-u_{i}, \mathrm{ui}=|\mathrm{U}| \\
& v i \sim \mathrm{N}\left[0, \sigma_{\mathrm{v}}^{2} \exp \left(\delta^{\prime} h i\right)\right] \\
& U \sim \mathrm{N}\left[0, \sigma_{\mathrm{u}}^{2}\right] .
\end{aligned}
$$

Using the Translog production function and including sector and an urban dummy, we fit the baseline and heteroscedastic stochastic frontier models using maximum likelihood and estimate the inefficiency terms in the stochastic frontier, $u_{i}$, by observation. The Jondrow et al. (1982) estimator $\widehat{E}\left[u_{i} \mid \varepsilon_{i}\right]$ is the standard estimator for inefficiency $u_{i}$. This is: 


$$
\begin{aligned}
& \widehat{E}\left[u_{i} \mid \varepsilon_{i}\right]=\left[\frac{\sigma \lambda}{1+\lambda^{2}}\right]\left[\frac{\phi(w)}{1-\Phi(w)}-w\right], \quad \varepsilon_{i}=v_{i}-u_{i}, \quad w=\frac{\lambda \varepsilon_{i}}{\sigma} \\
& \sigma=\sqrt{\sigma_{v}^{2}+\sigma_{u}^{2}}, \quad \lambda=\frac{\sigma_{u}}{\sigma_{v}}
\end{aligned}
$$

The properties of the estimated inefficiencies are examined to determine the preferred model as well as estimates of firm efficiency.

Subsequently, we proceed to examine the effect of assumed risk by firms on firm efficiency. As explained in the seminal review by Parmeter and Kumbhakar (2014), many studies have used a simpler, two-step analysis to model the influence of specific covariates on firm-level inefficiency. With this approach, authors construct estimates of inefficiency using the Jondrow et al. (1982) conditional mean in the first step, and then regress these inefficiency estimates on the exogenous variables in a second step (notably, these authors include Bravo-Ureta and Rieger 1991; Kalirajan 1990; Pitt and Lee 1981, among many others). 'This method has no statistical merit and duplication of this approach should be avoided' (Parmeter and Kumbhakar 2014: 52). ${ }^{3}$

In our case, we employ a single-step stage approach proposed by Greene $(2004,2018){ }^{4}$ This approach estimates the parameters of the relationship between efficiency and the explanatory variables, together with all the other parameters of the frontier model via maximum likelihood. In essence, this approach computes the marginal/partial effects of the explanatory variables (say $z$ ).

Following from the Jondrow et al. (1982) estimator for inefficiency in Eq. (6) and using notations in Greene (2018: E-27/28), efficiency can be stated as Efficiency $_{i}$ $=\exp \left\{-\widehat{E}\left[u_{i} \mid \varepsilon_{i}\right]\right\}$.

The presentation of the normal half normal model is a function of $w\left(\varepsilon_{i}\right)$ that is particular to the model. This can be written as:

$$
\text { Efficiency }_{i}=\exp \left\{-\tau_{m} A\left[w_{m}\left(\varepsilon_{i}\right)\right]\right\}
$$

where $m$ represents half normal, $\tau_{m}=\frac{\sigma \lambda}{1+\lambda^{2}}$ and $w_{m}$ are

\footnotetext{
${ }_{3}^{3}$ See Parmeter and Kumbhakar (2014) for detailed discussions on the biases that arise at various stages of this two-step procedure.

${ }^{4}$ The approach by Greene (2018) follows the half normal heteroscedastic model earlier proposed by Caudill and Ford (1993), Caudill et al. (1995), and Hadri et al. (2003).
}

specified in Eq. (6). Presuming that

$\varepsilon_{i}=y_{i}-\beta^{\prime} x_{i}+\delta^{\prime} z_{i}$

where $x$ are inputs and $z$ are the explanatory variables, we then need the derivatives with respect to our explanatory variables $z$. For convenience, we let $W=-w$ and exploit the symmetry of the normal density. Subsequently, $A\left[w_{m}\left(\varepsilon_{i}\right)\right]=\left[\frac{\phi(W)}{\Phi(W)}+W\right]$. Therefore, the derivative is

$$
\begin{aligned}
\partial \text { Efficiency } / \partial z= & \text { Efficiency } \times-\tau_{m} \times \frac{d A(W)}{d W} \times-1 \\
& \times \partial w_{m} / \partial \varepsilon \times-\delta
\end{aligned}
$$

The two terms that are needed to complete the derivation for the half normal model are $\partial w_{m} / \partial \varepsilon=\lambda / \sigma$ and $\frac{d A(W)}{d W}=\left[1-\frac{W \phi(W)}{\Phi(W)}-\left(\frac{\phi(W)}{\Phi(W)}\right)^{2}\right]=D(W)$.

Collecting terms, the derivative with respect to $z$ can be written as:

$$
\begin{aligned}
\frac{\partial \text { Efficiency }}{\partial z}= & \text { Efficiency } \times D(W) \\
& \times\left(\lambda^{2} /\left(1+\lambda^{2}\right) \times(1) \times(-\delta)\right.
\end{aligned}
$$

The Jondrow et al. (1982), estimator is used to estimate the partial effects of the $z$ variables on efficiency. We recast our preferred model for estimating firm efficiency to include our $z$ variables ${ }^{5}$ - that is, assumed risk of firm and some control variables which capture firm and owner characteristics that can affect firm productivity and examine how it impacts on firm efficiency. Following from the literature, the control variables include age of the firm, firm size, formal registration, percentage of sales for export, educational attainment of owner/manager, and an urban dummy.

Age-related effects on firm productivity can be largely explained by a range of factors, including scale economies gained as young firms grow over time and the likelihood of young firms employing new and improved technology or equipment. Younger firms therefore tend

\footnotetext{
${ }^{5}$ Greene (2018: 32), shows that "partial effects of variables in the stochastic frontier efficiency models may be computed with respect to any variable in any model, regardless of where those variables appear in the model'. This may include input variables in the original frontier model, exogenous variables in the means of the truncated regression formats and also in the variances of the heteroscedasticity models.
} 
to be more productive and grow faster than older firms (Colacelli and Hong 2019; Lopez-Garcia and Puente 2012; Barba Navaretti et al. 2014). With respect to firm size, larger firms may have a higher productivity due to economies of scale resulting from a greater allocative efficiency and the presence of fixed costs (see Bartelsman et al. 2013). The opposite case of diminishing productivity with firm size is also possible due to decreasing returns to scale. Several empirical studies have examined this relationship in detail (see Alvarez and Crespi 2003; De and Nagaraj 2014; Diaz and Sánchez 2008). Formal registration by firms may lead to access to public goods and services such as public infrastructure, bank support and credit, and better enforcement of property rights and contracts. Some studies have shown that formal registration leads to an increase in firm profit and productivity (Rand and Torm 2012; Sharma 2014). Also, firms that export may be exposed to knowledge flows from international buyers and competitors and to more intense competition in international markets which may lead to larger opportunities and incentives to improve productivity (see Alvarez and Lopez 2005; Eliasson et al. 2012). The educational attainment of the manager relates to the quality of management of a firm, and this has been found to impact firm productivity (Bloom and Van Reenen 2007; Syverson 2011). Urban areas can also offer agglomeration benefits, including larger markets, better infrastructure to access markets, and operating a larger pool of workers, among others. These benefits are likely to affect firm productivity positively (see Rand et al. 2019; Rosenthal and Strange 2004).

4.2 Estimating the relationship between assumed risk and institutions

Adopting the specification by Steer and Sen (2010), we estimate the following probit model using assumed risk as the endogenous variable:

$$
A R_{i}=\alpha I N F_{i}+\beta F M L_{i}+\gamma L K I_{i}+\delta C T R_{i}+\mu_{i}
$$

$A R$ is assumed risk of firm $i$ in its relationship with customers. In this study, we use asset specificity to measure assumed or transaction risk. We measure assumed or transaction risk as investments that firms make in physical or human assets to meet the needs of a specific customer. Thus, we measure $A R$ with respect to risk taken by firms in their relationship with customers by whether or not a firm has made any specific investments in equipment or trained their workers specifically to supply a particular customer. These measures of assumed or transaction risk have been used extensively in the empirical transaction cost literature (see Boerner and Macher 2001; Hendley and Murrell 2003; Richman and Macher 2006; Steer and Sen 2010).

INF represents informal institutions and captures mechanisms of information acquisition available to firms on customers as well as bilateral and multilateral networks. The variables used here include own information from informal interaction with customer; whether customer is foreign; whether first information about customer is from family and friends, and/or business network; whether firm talks to other suppliers about customers; and whether firm is a member of a business association. FML is formal institutions and is measured as the percentage of total sales based on formal written contracts with customers; $L K I$ measures the degree of lock-in. As indicated by Steer and Sen (2010), a customer can be locked in a relationship with a firm if few alternative suppliers of that particular product are available. This could be due to high search or transportation costs and therefore in this case, bilateral relationships and networks become more effective. In capturing $L K I$, we use the variable 'approximately how many competitors do the firm currently have?'. CTR is a vector controlling for sector, location (state/region), and firm characteristics (such as size), and $\mu_{i}$ is the error term.

\section{Data}

We use data from the Myanmar Enterprise Monitoring Survey (MEMS) project by the United Nations University World Institute for Development Economics Research (UNU-WIDER) and the Central Statistical Organization (CSO) of the Ministry of Planning and Finance of Myanmar. The survey is a nationally representative enterprise survey, conducted in 2017, which focuses on and provides a unique dataset on small and medium enterprises (SMEs) in the manufacturing sector (CSO and UNU-WIDER 2018). The data was collected in 2017 in 35 townships in all 15 regions and states of the country, including the Nay Pyi Taw Union Council. The sample comprises 2496 enterprises and 6722 employees and is statistically representative of more than 71,000 manufacturing firms in Myanmar. A stratified 
sampling approach was used to select enterprises. Classification of firms is done based on the number of fulltime and part-time workers, following the cut-off points proposed by the World Bank. Micro enterprises are those with 1-9 employees, small-scale enterprises are those with 10-49 employees, medium-sized enterprises are those with 50-299 employees, and large enterprises are those with more than 300 employees. The main questionnaire was administered to enterprise owners or managers. It included information on enterprise characteristics and practices, such as number and structure of workforce, technology and innovation, investment, regulatory framework, revenues and costs, customers, owner characteristics, and perceptions about the constraints and potentials of the business environment. ${ }^{6}$ Detailed description of the characteristics of surveyed firms and summary statistics is presented in Online Appendix A.2.

\section{Empirical results}

In this section, we first present the productivity estimates for firms in Myanmar obtained from the stochastic frontier analysis. We then examine the relationship between firm productivity and assumed risk. Finally, we analyse the institutional determinants of assumed risk.

\subsection{Stochastic frontier models: results and analysis}

In this section, we discuss the properties of the estimated inefficiencies for models (1)-(5) and settle on a preferred model. Table 2 summarizes the relevant diagnostic tests using our baseline model to ensure validity of the econometric approach adopted in this study. Following from the generalized LR-test statistic, the null hypothesis of no inefficiency is rejected, while the Translog production function is suitable at the $5 \%$ significance level. The rejection of the null of no inefficiency effects provides support for the stochastic frontier model specification. Table 3 presents the estimated stochastic production frontier function for all specifications discussed in Section 4.1.

The inefficiency estimates of all five specifications are highly correlated (see Table B1 in Online Appendix B.1), indicating that the models are consistent. The pattern of the correlation plots also shows that the

\footnotetext{
${ }^{6}$ More detailed information about sampling is available in CSO and UNU-WIDER (2018).
}

baseline model is very similar to the heteroscedastic model which introduces $h_{i}$ in the frontier function itself. In fact, the correlation between the baseline model and the heteroscedastic models show that the baseline model is highly correlated with the heterogeneity in frontier model and the variance in $u_{i}$ model. The correlation is smaller between the baseline model and the heteroscedastic variance in $v_{i}$ model (see Fig. 1).

However, the mean and variation of the distribution for the estimated inefficiencies show some more differences. The kernel densities show that the mean and distribution of the baseline model are fairly large (see Fig. 2). The mean and deviation of the heteroscedastic model which control for heterogeneity in the frontier function and in the variance of $u_{i}$ are also very similar to the baseline. The mean of the heteroscedastic model which accounts for heterogeneity in the mean of the underlying distribution of $u_{i}$ is somewhat smaller but relatively more dispersed than the others. The mean of the model which treats heterogeneity in the variance of $v_{i}$ is also relatively small but, more importantly, much tighter than all the others.

The unreasonable and extremely large estimates and standard errors of variance parameters for compound errors $(\lambda$ and $\sigma)$ as well as the distribution of $\sigma_{u}$ and $\sigma_{v}$ in the truncated model (see column 4, Table 3 ) do show that there is something wrong with this model. The heteroscedastic model, which allows for observable variation in $\sigma_{v}^{2}$, seems more preferable. Compared to the baseline homoscedastic model, the analysis above shows that the heteroscedastic model which treats heterogeneity in the variance of $v_{i}$ undoubtedly illustrates the influence of heterogeneity (see Fig. 2). ${ }^{7}$ Using the preferred Het. in variance of $v_{i}$ model, the average efficiency of a firm in Myanmar is around 34\%. The summary statistics of firm efficiency for all models and firm efficiency by size of firm using the heterogeneity in variance of $v_{i}$ model is shown in Online Appendix B.2.

\subsection{Assumed risk and firm efficiency}

Turning our focus to the impact of assumed risk by firms on firm productivity, we recast the heterogeneity in variance of $v_{i}$ model in Eq. (5) to include our $z$ variables:

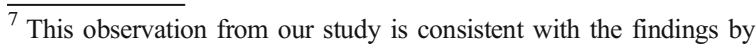
studies that examine the consequences of ignoring heteroscedasticity in the stochastic frontier, particularly ignoring heteroscedasticity of $v_{i}$. (see Greene 2004; Kumbhakar and Lovell 2000; Parmeter and Kumbhakar 2014).
} 
Table 3 Estimated stochastic frontier models (with sector dummies)

\begin{tabular}{|c|c|c|c|c|c|}
\hline Parameters & Baseline & Het. in frontier & Het. in mean in the truncation & Het. in variance of $u_{i}$ & Het. in variance of $v_{i}$ \\
\hline Constant & $17.298 * * *(0.450)$ & $17.280 * * *(0.455)$ & $16.996 * * *(0.428)$ & $17.086 * * *(0.446)$ & $16.978 * * *(0.463)$ \\
\hline Ln capital stock $(K)$ & $-0.205 * * *(0.046)$ & $-0.198 * * *(0.046)$ & $-0.245 * * *(0.041)$ & $-0.231 * * *(0.043)$ & $-0.186^{* * *}(0.043)$ \\
\hline Ln labour $(L)$ & $0.755 * * *(0.133)$ & $0.762 * * *(0.133)$ & $0.758 * * *(0.125)$ & $0.776 * * *(0.137)$ & $0.814 * * *(0.147)$ \\
\hline$K^{2}$ & $0.013 * * *(0.002)$ & $0.012 * * *(0.002)$ & $0.014 * * *(0.001)$ & $0.013 * * *(0.002)$ & $0.012 * * *(0.002)$ \\
\hline$L^{2}$ & $0.005(0.016)$ & $0.002(0.016)$ & $0.003(0.015)$ & $0.009(0.016)$ & $0.001(0.017)$ \\
\hline$K \times L$ & $-0.002(0.007)$ & $-0.003(0.007)$ & $-0.001(0.007)$ & $-0.001(0.007)$ & $-0.005(0.008)$ \\
\hline Technology1 & $-0.257 * *(0.109)$ & $-0.234 * *(0.109)$ & $-0.293 * * *(0.101)$ & $-0.202 *(0.108)$ & $-0.243 * *(0.104)$ \\
\hline Technology3 & $0.414 * * *(0.101)$ & $0.418 * * *(0.101)$ & $0.407 * * *(0.100)$ & $0.534 * * *(0.109)$ & $0.426 * * *(0.106)$ \\
\hline Technology4 & $0.314 * * *(0.087)$ & $0.314 * * *(0.087)$ & $0.341 * * *(0.085)$ & $0.461 * * *(0.089)$ & $0.303 * * *(0.089)$ \\
\hline Urban & $-0.009(0.085)$ & $-0.034(0.087)$ & $0.053(0.086)$ & $0.033(0.096)$ & $-0.030(0.088)$ \\
\hline Ind. zone & - & $0.185 * *(0.085)$ & - & - & - \\
\hline Access to elect. & - & $-0.031(0.098)$ & - & - & - \\
\hline Sector dummies & Yes & Yes & Yes & Yes & Yes \\
\hline \multicolumn{6}{|c|}{ Parameters in mean of $u /$ in variance of $u$ and $v$} \\
\hline Constant & - & - & $-335.540(1817.091)$ & $0.981 * * *(0.141)$ & $0.285 * * *(0.081)$ \\
\hline Ind. zone & - & - & $85.192(449.599)$ & $0.602 * * *(0.066)$ & $0.913 * * *(0.066)$ \\
\hline Access to elect. & - & - & $26.345(280.057)$ & $0.054(0.126)$ & $-0.049(0.082)$ \\
\hline \multicolumn{6}{|c|}{ Variance parameters for compound error } \\
\hline$\lambda$ & $1.543 * * *(0.058)$ & $1.565 * * *(0.0 .59)$ & $14.557(76.733)$ & 1.524 & 1.222 \\
\hline$\sigma$ & $2.165 * * *(0.001)$ & $2.171 * * *(0.001)$ & $17.286(90.869)$ & 2.168 & 2.041 \\
\hline$\sigma_{u}$ & 1.817 & 1.830 & 17.245 & 1.812 & 1.579 \\
\hline$\sigma_{v}$ & 1.177 & 1.169 & 1.184 & 1.189 & 1.292 \\
\hline
\end{tabular}

Technology1, Technology3, and Technology4 are dummies for firms using hand tools, only power, and both power and manually driven machines respectively. Technology 2 representing firms using manually driven machines is dropped due to multicollinearity. $* * *, * *$, and $*$ denote significance at $1 \%, 5 \%$, and $10 \%$ respectively. Estimated standard errors are in parenthesis

assumed risk of firms and the control variables - age of the firm, firm size, formal registration, percentage of sales for export, and educational attainment of owner/ manager. In this case, our $z$ variables appear in the variance of $v_{i}$ in our heteroscedastic model. The model is estimated using maximum likelihood. We then discuss the partial effects for the Jondrow et al. (1982) estimator in the stochastic frontier model. Table 4 presents partial effects of assumed risk on firm efficiency. ${ }^{8}$

The results show that the assumed risk of firms has a positive and statistically significant effect on firm productivity. Firms that engage in risk taking increase their productivity by $0.5 \%$ more on average than firms that do not. Assumed risk by firms is therefore productivity enhancing in Myanmar. In effect, risk taken by firms

\footnotetext{
${ }^{8}$ Descriptive analysis of efficiency levels for firms that take risk versus firms that do not take risk, across firm size, is presented in Online Appendix C.1.
}

in their relationships with customers, with respect to any firm-specific investments in equipment or training of workers specifically to supply a particular customer, significantly influences the efficiency and performance of the firm. This finding thus lends support to those researchers who argue that specific investments, particularly in training workers and in specialized equipment, influence productivity growth (see Bloom et al. 2014; McKenzie and Woodruff 2014). With respect to the control variables, the age of the firm and the number of workers have a significantly negative impact on firm productivity. In this case, younger firms are significantly more productive, as shown in the literature (see LopezGarcia and Puente 2012; Barba Navaretti et al. 2014). As the firm size increases, firm productivity declines by $8.5 \%$ in Myanmar. With respect to the educational attainment of a firm owner or manager, having primary education significantly impacts firm productivity 
Fig. 1 Correlation of inefficiency estimates between baseline homoscedastic and heteroscedastic models
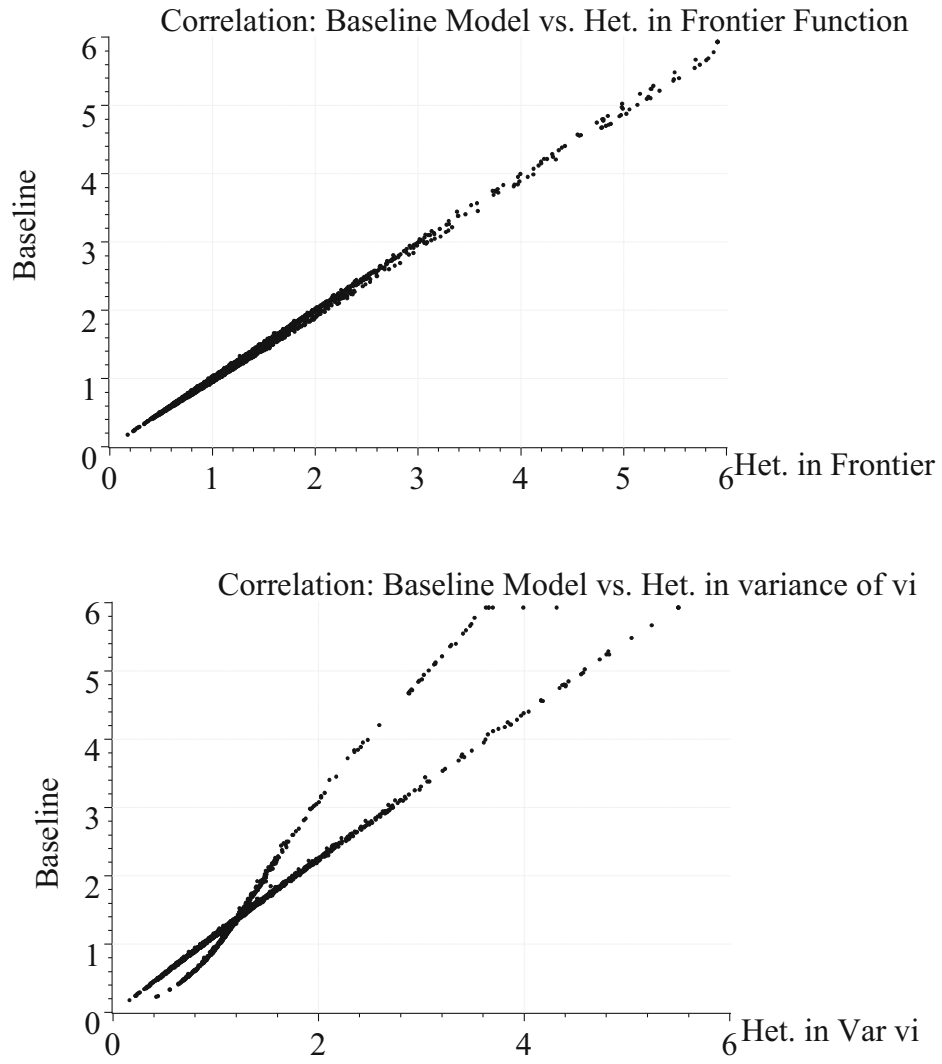

positively, while the effect of having tertiary education is also positive but insignificant. Therefore, more formal education does not seem to induce firm productivity in
Myanmar. This surprising finding, however, requires further research. Formal firm registration and the firm being located in an urban area are also positively
Fig. 2 Kernel densities for inefficiency: all models

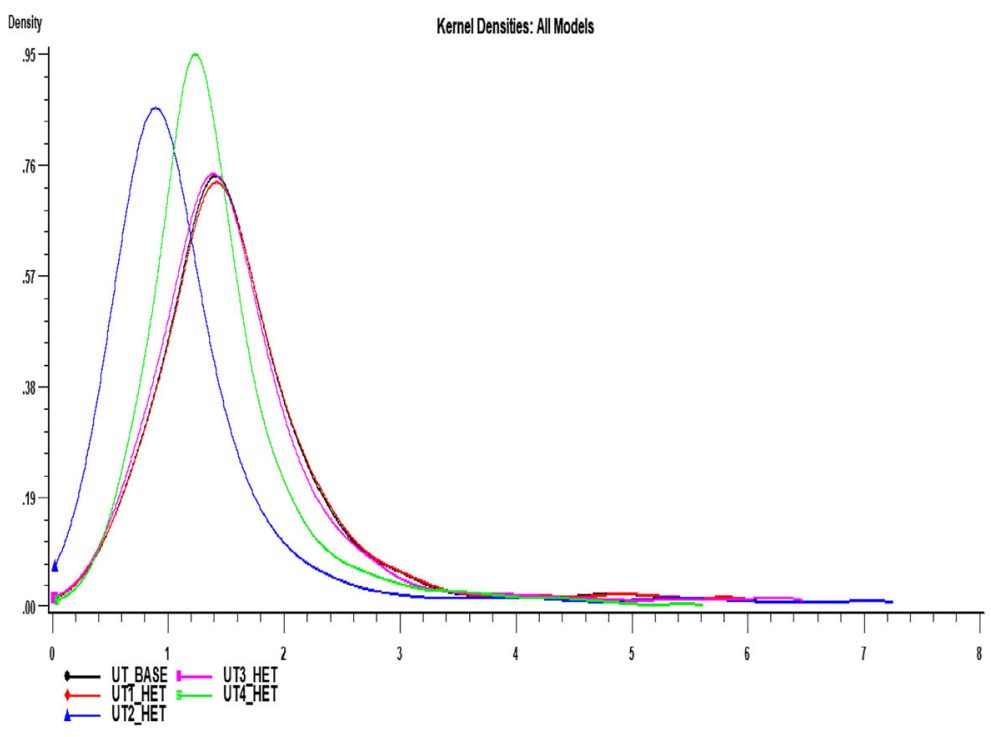


Table 4 Partial effects for Het. in variance of $v_{i}$ stochastic frontier model

\begin{tabular}{ll}
\hline Variables & Coeff. \\
\hline Assumed risk (d) & $0.00503 * * *(0.00190)$ \\
Log age of firm (c) & $-0.00728 * * *(0.0011)$ \\
Formal registered (d) & $0.00028(0.00194)$ \\
$\%$ of sales for export (c) & $-0.00006(0.00006)$ \\
Log no. of workers (c) & $-0.08547 * *(0.01486)$ \\
Primary (d) & $0.01591 * * *(0.00502)$ \\
Secondary (d) & $0.00087(0.00403)$ \\
Vocational/diploma (d) & $-0.00877(0.00627)$ \\
Tertiary (d) & $0.00432(0.00418)$ \\
Urban (d) & $0.00441(0.00784)$ \\
No. of observations & 2496
\end{tabular}

Parameters of the Translog stochastic frontier production function are omitted for the sake of brevity

$* * *, * *$, and $*$ denote significance at $1 \%, 5 \%$, and $10 \%$ respectively. Estimated standard errors are in parenthesis

(c) and (d) represent continuous and dummy variable respectively

associated with firm productivity, albeit not statistically significant.

\subsection{Assumed risk and informal institutions}

Table 5 presents the determinants of the risk assumed by firms. To ensure robustness of our regression estimates, we first run our model without the control variables (column 1), and then in column 2, we include our control variables but use the location of Yangon instead of state dummies. In column 3, we introduce state dummies as part of the control variables. The ensuing discussion focuses on the role of informal institutions in determining whether firms engage in risky transactions.

Beginning with information exchange and firms' interaction with customers, we find that information from informal interaction with customers significantly influences the risk assumed by firms positively, while the percentage of customers that are foreign does not have any effect on firms' propensity to take risk. Firms that receive information from informal interaction with customers have a 6.4 percentage point higher probability of making specific investment than firms that do not.

With respect to social and business networks, information received by firms from business networks, talking to other suppliers of customers, and being a member of a business association significantly affect the likelihood of a firm taking larger risk. The probability of making specific investment if firms receive information from business networks is raised by 8.1 percentage points. If firms talk to other suppliers of their customer, the predicted probability of investing increases significantly by 15.5 percentage points. Firms that are members of a business association have a 9.8 percentage point higher propensity of taking risk than non-members. Information from personal contacts does not determine the willingness of a firm to bear a degree of assumed risk in Myanmar.

In relation to formal institutions, firms are found to be willing to take significantly larger risk (by 0.2 percentage points) as the percentage of their sales based on written contracts increases. This small magnitude in terms of response by firms may be due largely to the weak enforcement of contracts and the prevailing quality of judicial processes. With respect to the locked-in behaviour by firms, the number of competitors does not seem to significantly affect firms' propensity to take larger risk.

With respect to the controls, a $100 \%$ increase in the number of workers increases the probability of firms making specific investment by 2.5 percentage points, while location in Yangon decreases the propensity of a firm to bear assumed risk by 15.3 percentage points.

Further analysis, carried out to examine the role of informal institutions on assumed risk based on the size of the firm, showed that informal institutions play a significant role in the propensity of small firms to take larger risk, but this is not the case for medium and large firms in Myanmar. Detailed description of results is presented in Online Appendix D.1.

\section{Conclusion and policy implications}

A feature of developing countries is the existence of a large number of unproductive firms, which leads to a low level of overall productivity for the economy (Bloom et al. 2014). Understanding what explains this low productivity among many firms in developing countries is of fundamental importance in understanding what drives economic growth in the developing country context and finding ways to reduce gap in living standards between rich and poor countries. In this paper, we examine the institutional factors that may explain low productivity in a low-income transition economy- 
Table 5 Marginal effects of formal and informal institutions on assumed risk

Specific investment

(1)

(2)

(3)

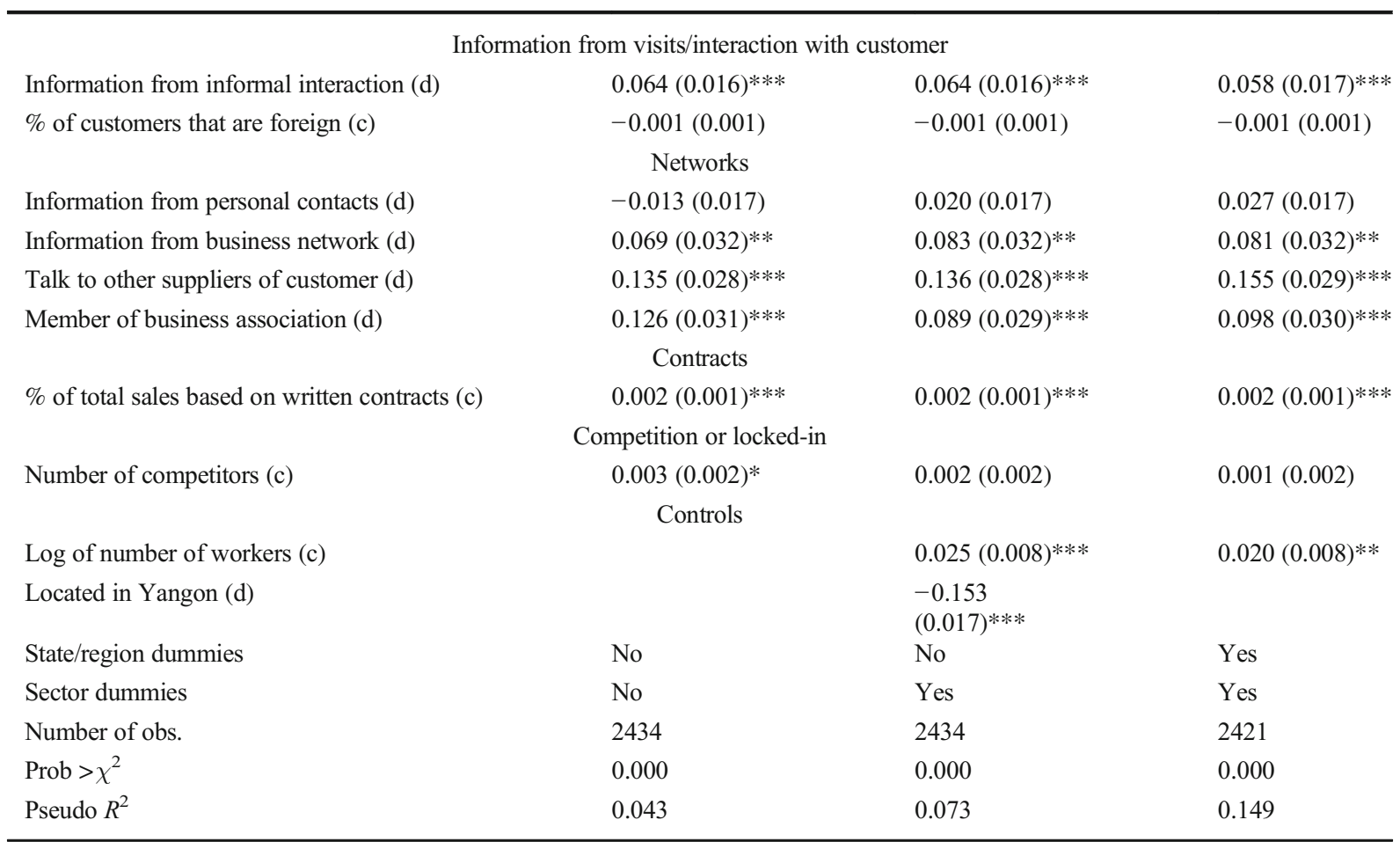

$* * *, * *$, and $*$ denote significance at $1 \%, 5 \%$, and $10 \%$ respectively. Estimated standard errors are in parenthesis. (c) and (d) represent continuous and dummy variable respectively

Myanmar-with a specific focus on informal institutions.

Using a rich firm-level dataset that spans micro, small, and large firms, and using stochastic frontier analysis to estimate firm-level productivity, we find that firms which assume higher transactions risks have higher levels of productivity. Furthermore, we find that informal institutions, such as relational contracting and social networks, contribute to greater risk taking by firms, even in a context where formal institutions do not work well. This finding is consistent with the new institutional economics literature, which highlights the role that informal institutions can play when formal institutions are either missing or do not function well. Our findings suggest that relational contracting and social networks can be efficiency enhancing in lowincome country contexts where courts and formal dispute resolution procedures may take time to develop. Therefore, our findings can be generalizable to other low-income Asian and African countries where formal institutional reforms have not had the desired positive effect on economic growth (such as Nepal in South Asia and Mozambique in Sub-Saharan Africa).

Though we find in the Myanmar context that informal institutions have been effective in allowing firms to engage in more complex transactions, we also find that the use of written contracts is associated with greater risk taking by firms. This suggests that informal and formal institutions are not substitutes in the process of economic development, and the role of policy is to find synergies between these two sets of institutions so that they can be complements to each other in the process of economic development. For a low-income transition economy like Myanmar, while the presence of informal institutions has allowed firms to take risks with their investment, it is also important from a policy point of view that formal institutions of contracting and dispute resolution are strengthened over time. 
One limitation of our analysis is that the use of crosssectional data in our stochastic frontier analysis does not allow us to account for unobserved or latent heterogeneity in our modelling. The lack of information on firms over time also does not allow us to study whether inefficiency has been persistent over time or whether the inefficiency of firms is time varying. A panel dataset in this case will be more useful in our modelling and analysis (see Schmidt and Sickles 1984). Further surveys of the same firms over time would allow us to control for time-invariant unobserved characteristics of these firms as well as allow us to examine whether the role of formal institutions in determining assumed risk and, consequently, firm performance has increased over time, as these institutions evolve and mature with Myanmar's economic development.

Supplementary Information The online version contains supplementary material available at https://doi.org/10.1007/s11187020-00441-w.

Open Access This article is licensed under a Creative Commons Attribution 4.0 International License, which permits use, sharing, adaptation, distribution and reproduction in any medium or format, as long as you give appropriate credit to the original author(s) and the source, provide a link to the Creative Commons licence, and indicate if changes were made. The images or other third party material in this article are included in the article's Creative Commons licence, unless indicated otherwise in a credit line to the material. If material is not included in the article's Creative Commons licence and your intended use is not permitted by statutory regulation or exceeds the permitted use, you will need to obtain permission directly from the copyright holder. To view a copy of this licence, visit http://creativecommons.org/licenses/by/4.0/.

\section{References}

Aigner, D., Lovell, C. K., \& Schmidt, P. (1977). Formulation and estimation of stochastic frontier production function models. Journal of Econometrics, 6(1), 21-37. https://doi. org/10.1016/0304-4076(77)90052-5.

Alvarez, R., \& Crespi, G. (2003). Determinants of technical efficiency in small firms. Small Business Economics, 20(3), 233-244. https://doi.org/10.1023/A:1022804419183.

Alvarez, R., \& Lopez, R. A. (2005). Exporting and performance: evidence from Chilean plants. Canadian Journal of Economics/Revue Canadienne d'économique, 38(4), 1384 1400. https://doi.org/10.1111/j.0008-4085.2005.00329.x.

Barba Navaretti, G., Castellani, D., \& Pieri, F. (2014). Age and firm growth: evidence from three European countries. Small
Business Economics, 43(4), 823-837. https://doi. org/10.1007/s11187-014-9564-6.

Bartelsman, E., Haltiwanger, J., \& Scarpetta, S. (2013). Crosscountry differences in productivity: the role of allocation and selection. American Economic Review, 103(1), 305-334. https://doi.org/10.1257/aer.103.1.305.

Bissinger, J. (2014). Myanmar's economic institutions in transition. Journal of Southeast Asian Economies, 241-255. https://doi.org/10.1355/ae31-2f.

Bloom, N., \& Van Reenen, J. (2007). Measuring and explaining management practices across firms and countries. The Quarterly Journal of Economics, 122(4), 1351-1408. https://doi.org/10.1162/qjec.2007.122.4.1351.

Bloom, N., Lemos, R., Sadun, R., Scur, D., \& Van Reenen, J. (2014). JEEA-FBBVA lecture 2013: 'the new empirical economics of management'. Journal of the European Economic Association, 12(4), 835-876. https://doi.org/10.1111 /jeea.12094.

Boerner CS, Macher JT (2001) 'Transaction cost economics: an assessment of empirical research in the social sciences'. Unpublished manuscript. Washington, D.C.: Georgetown University.

Børing, P. (2019). The relationship between firm productivity, firm size and CSR objectives for innovations. Eurasian Business Review, 9, 269-297.

Bravo-Ureta, B. E., \& Rieger, L. (1991). Dairy farm efficiency measurement using stochastic frontiers and neoclassical duality. American Journal of Agricultural Economics, 73(2), 421-428. https://doi.org/10.2307/1242726.

Caudill, S. B., \& Ford, J. M. (1993). Biases in frontier estimation due to heteroscedasticity. Economics Letters, 41(1), 17-20. https://doi.org/10.1016/0165-1765(93)90104-K.

Caudill, S. B., Ford, J. M., \& Gropper, D. M. (1995). Frontier estimation and firm-specific inefficiency measures in the presence of heteroscedasticity. Journal of Business \& Economic Statistics, 13(1), 105-111. https://doi. org/10.1080/07350015.1995.10524583.

Coase, R. (1937). Transactions cost economics: the natural progression. American Economic Review, 100, 673-690.

Colacelli, M., \& Hong, M. G. H. (2019). Productivity drag from small and medium-sized enterprises in Japan. Washington, DC: International Monetary Fund.

CSO \& UNU-WIDER (2018). Myanmar Enterprise Monitoring Survey (MEMS) Dataset. Central Statistical Organization: Nay Pyi Taw and UNU-WIDER: Helsinki.

Danquah, M., \& Ouattara, B. (2015). What drives National Efficiency in sub-Saharan Africa. Economic Modelling, 44, 171-179. https://doi.org/10.1016/j.econmod.2014.10.019.

De Long, J. B., \& Summers, L. H. (1991). Equipment investment and economic growth. The Quarterly Journal of Economics, 106(2), 445-502. https://doi.org/10.2307/2937944.

De Long, J. B., Summers, L. H., \& Abel, A. B. (1992). Equipment investment and economic growth: how strong is the nexus?. Brookings Papers on Economic Activity, 1992(2), 157-211.

De, P. K., \& Nagaraj, P. (2014). Productivity and firm size in India. Small Business Economics, 42(4), 891-907.

Dethier, J. J., Hirn, M., \& Straub, S. (2011). Explaining enterprise performance in developing countries with business climate survey data. The World Bank Research Observer, 26(2), 258-309. https://doi.org/10.1093/wbro/lkq007. 
Diaz, M. A., \& Sánchez, R. (2008). Firm size and productivity in Spain: A stochastic frontier analysis. Small Business Economics, 30(3), 315-323. https://doi.org/10.1007 /s11187-007-9058-x.

Duffy, J., \& Papageorgiou, C. (2000). A cross-country empirical investigation of the aggregate production function specification. Journal of Economic Growth, 5(1), 87-120. https://doi. org/10.1023/A:1009830421147.

Eliasson, K., Hansson, P., \& Lindvert, M. (2012). Do firms learn by exporting or learn to export? Evidence from small and medium-sized enterprises. Small Business Economics, 39(2), 453-472. https://doi.org/10.1007/s11187-010-9314-3.

Escandon-Barbosa, D., Urbano-Pulido, D., \& Hurtado-Ayala, A. (2019). Exploring the relationship between formal and informal institutions, social capital and entrepreneurial activity in developing and developed countries. Sustainability, 11(550), $1-20$.

Fafchamps, M. (2016). Formal and informal market institutions: embeddedness revisited. In Stanford University working paper. Stanford: Stanford University.

Gogokhia, T., \& Berulava, G. (2020). Business environment reforms, innovation and firm productivity in transition economies. Eurasian Business Review, 1-25.

Greene, W. H. (1990). A gamma-distributed stochastic frontier model. Journal of Econometrics, 46(1-2), 141-163.

Greene, W. (2004). Distinguishing between heterogeneity and inefficiency: stochastic frontier analysis of the World Health Organization's panel data on National Health Care Systems. Health Economics, 13(10), 959-980. https://doi. org/10.1002/hec.938.

Greene, W. H. (2018). Econometric analysis/LimDep users manual. New York: Econometric Software, Inc.

Greenstone, M., Hornbeck, R., \& Moretti, E. (2010). Identifying agglomeration spillovers: evidence from winners and losers of large plant openings. Journal of Political Economy, 118(3), 536-598. https://doi.org/10.1086/653714.

Grief, A. (2006). Institutions and the path to the modern economy. Cambridge: Cambridge University Press.

Hadri, K., Guermat, C., \& Whittaker, J. (2003). Estimation of technical inefficiency effects using panel data and doubly heteroscedastic stochastic production frontiers. Empirical Economics, 28(1), 203-222. https://doi.org/10.1007 /s001810100127.

Hall, B. H., Lotti, F., \& Mairesse, J. (2013). Innovation and productivity in SMEs: empirical evidence for Italy. Small Business Economics, 33(1), 13-33.

Hendley, K., \& Murrell, P. (2003). Which mechanisms support the fulfillment of sales agreements? asking decision-makers in firms. Economics Letters, 78(1), 49-54. https://doi. org/10.1016/S0165-1765(02)00177-5.

Hu, C., Xu, Z., \& Yashiro, N. (2015). Agglomeration and productivity in China: firm level evidence. China Economic Review, 33, 50-66. https://doi.org/10.1016/j.chieco.2015.01.001.

Hwang, P. (2006). Asset specificity and the fear of exploitation. Journal of Economic Behaviour and Organisation, 60, 423438.

Jondrow, J., Lovell, C. K., Materov, I. S., \& Schmidt, P. (1982). On the estimation of technical inefficiency in the stochastic frontier production function model. Journal of Econometrics, 19(2-3), 233-238.
Kalirajan, K. P. (1990). On measuring economic efficiency. Journal of Applied Econometrics, 5(1), 75-85. https://doi. org/10.1002/jae.3950050106.

Kandori, M. (1992). Social norms and community enforcement. The Review of Economic Studies, 59(1), 63-80. https://doi. org/10.2307/2297925.

Khin, M. K., Findlay, R., Sundram, R. M., Mya, M., Myo, N., \& Zaw, O. (2000). Economic development of Burma: a vision and a strategy. Stockholm: Olof Palme International Center.

Kodde, D. A., \& Palm, F. C. (1986). Wald criteria for jointly testing equality and inequality restrictions (pp. 1243-1248). Econometrica: Journal of the Econometric Society. https://doi.org/10.2307/1912331.

Kumbhakar, S. L., \& Lovell, K. (2000). Stochastic frontier analysis. Cambridge: Cambridge University Press.

Lopez-Garcia, P., \& Puente, S. (2012). What makes a high-growth firm? A dynamic probit analysis using Spanish firm-level data. Small Business Economics, 39(4), 1029-1041.

McKenzie, D., \& Woodruff, C. (2014). What are we learning from business training and entrepreneurship evaluations around the developing world? The World Bank Research Observer, 29(1), 48-82. https://doi.org/10.1093/wbro/lkt007.

McMillan, J. (1997). 'A study of economic reform, ed. by Brian Silverstone'.: Amsterdam [u. a.], Elsevier, 1996. Journal of Economic Literature, 35(4), 2094-2095.

McMillan, J., \& Woodruff, C. (1999). Interfirm relationships and informal credit in Vietnam. The Quarterly Journal of Economics, 114(4), 1285-1320. https://doi.org/10.1162 /003355399556278.

Min, A., \& Kudo, T. (2013). New government's initiatives for industrial development in Myanmar. In H. Lim \& Y. Yamada (Eds.), Economic reforms in Myanmar: pathways and prospects (pp. 39-84). Bangkok: Bangkok Research Centre.

North, D.C., (1994a). Institutions and Productivity in History, Economic History 9411003. Munich: University Library of Munich.

North, D. C. (1994b). Economic performance through time. The American Economic Review, 84(3), 359-368.

Nunn, N. (2007). Relationship-specificity, incomplete contracts, and the pattern of trade. The Quarterly Journal of Economics, 122(2), 569-600. https://doi.org/10.1162/qjec.122.2.569.

OECD (2013). Multi-dimensional review of Myanmar 2013. Organisation for Economic Co-operation and Development Publishing.

OECD (2015). Multi-dimensional review of Myanmar - an initial assessment. Paris: Organisation for Economic Co-operation and Development.

Parmeter, C. F., \& Kumbhakar, S. C. (2014). Efficiency analysis: a primer on recent advances. Foundations and Trends in Econometrics, 7(3-4), 191-385. https://doi.org/10.1561 /0800000023.

Pellegrino, G., \& Piva, M. (2020). Innovation, industry and firm age: Are there new knowledge production functions? Eurasian Business Review, 10, 65-95.

Pitt, M. M., \& Lee, L. F. (1981). The measurement and sources of technical inefficiency in the Indonesian weaving industry. Journal of Development Economics, 9(1), 43-64. https://doi.org/10.1016/0304-3878(81)90004-3.

Putnam, R. (2000). Bowling alone: the collapse and revival of American community. New York: Simon and Schuster. 
Rand, J., \& Torm, N. (2012). The benefits of formalization: Evidence from Vietnamese manufacturing SMEs. World Development, 40(5), 983-998. https://oi.org/10.1016/j. worlddev.2011.09.004.

Rand, J., Tarp, F., Trifković, N., \& Zille, H. (2019). 'Industrial agglomeration in Myanmar'. WIDER Working Paper 2019/3. Helsinki: UNU-WIDER. https://doi.org/10.35188 /UNU-WIDER/2019/637-1.

Richman, B. M. J., \& Macher, J. (2006). 'Transaction cost economics: an assessment of empirical research in the social sciences'. Duke Law School Legal Studies Paper 115. Durham: Duke University School of Law, mimeo.

Robertson, B., \& Taung, M. S. (2015). Industrial zones in Myanmar: diagnostic review and policy recommendations. Bonn: Friedrich-Naumann-Stiftung für die Freiheit.

Rosenthal, S. S., \& Strange, C. W. (2004). Evidence on the nature and sources of agglomeration economies. Handbook of Regional and Urban Economics, 4, 2119-2171. https://doi. org/10.1016/S1574-0080(04)80006-3.

Ruggiero, J. (1999). Efficiency estimation and error decomposition in the stochastic frontier model: A Monte Carlo analysis. European Journal of Operational Research, 115(3), 555-563.

Schmidt, P., \& Sickles, R. C. (1984). Production frontiers and panel data. Journal of Business \& Economic Statistics, 2(4), 367-374.

Sharma, S. (2014). Benefits of a registration policy for microenterprise performance in India. Small Business Economics, 42(1), 153-164. https://doi.org/10.1007/s11187-013-9475-y.

Shelanski, H., \& Klein, P. (1995). Empirical research in transactions cost economics: a review and an assessment. Journal of Law, Economics and Organisation, 11(2), 335-361.
Steer, L., \& Sen, K. (2010). Formal and informal institutions in a transition economy: the case of Vietnam. World Development, 38(11), 1603-1615. https://doi.org/10.1016/j. worlddev.2010.03.006.

Svejnar, J. (2002). Transition economies: performance and challenges. Journal of Economic Perspectives, 16(1), 3-28.

Syverson, C. (2011). What determines productivity? Journal of Economic Literature, 49(2), 326-365. https://doi. org/10.1257/jel.49.2.326.

Tin, M. M. T. (2006). State dominance in Myanmar: the political economy of industrialization. Singapore: Institute of South East Asian Studies.

Turnell, S. (2009). Fiery dragons: banks, finance and money lenders in Burma. Copenhagen: NIAS Press.

UNESCAP. (2015). Myanmar business survey. Bangkok: United Nations Economic and Social Commission for Asia and the Pacific.

Williamson, O. E. (1985). The economic institutions of capitalism. London: Macmillan.

Williamson, O. E. (1996). The mechanisms of governance. Oxford: Oxford University Press.

Williamson. (2010). Transactions cost economics: the natural progression. American Economic Review, 100, 673-690.

World Bank. (2020). Doing business report 2020. Washington, DC: The World Bank.

Publisher's note Springer Nature remains neutral with regard to jurisdictional claims in published maps and institutional affiliations. 